\title{
FACTORS INFLUENCING TRADE AREA ACTIVITY IN THE GREAT BASIN AREA
}

\author{
George Ebai and Thomas R. Harris
}

\begin{abstract}
Proper assessment of rural retail sector activity would yield effective and targeted retail extension/outreach programs. Pull factors assess a local retail sector's ability to meet local retail demands and to capture outside trade. If the local retail sector's pull factor value is above the threshold value of one, the local retail sector is capturing local and non-local retail demands. Tobit estimation procedures were used for eight retail sectors to determine factors which influence the capture of local and non-local retail demands. These significant factors were derived and discussed as elements to be implemented into future retail extension/outreach programs.
\end{abstract}

\section{INTRODUCTION}

Industrial recruitment and retail sector revitalization continue to be the two most common economic development strategies employed by communities (Daniels 1989). A community employing only industrial recruitment may however be restricting its economic development options. Pulver (1979) offers a more expansive range of economic development strategies which may offer additional economic development alternatives for rural areas. ${ }^{1}$

One such strategy is for a community to improve its ability to capture local retail expenditures. Recently, economists and planners have conducted research and outreach programs across the nation to help local economic development practitioners adequately address problems in their local retail sector. ${ }^{2}$ In addition, the extension service of the USDA has targeted programs to increase the viability of rural retail sectors as a national program priority. ${ }^{3}$

A successful outreach program focuses on improving the capture of local retail demands. To develop such a strategy, information from an analysis of local retail sales potential and its capture is required. Sales retention is an indirect measure of locally available goods and services assuming local people would buy locally if the product or service was available and competitively priced

\footnotetext{
"George E. Ebai is a Research Associate in the Department of Applied Economics at the University of Nevada, Reno. Thomas R. Harris is a Professor and Director of the University Center for Economic Development at the University of Nevada, Reno. The authors would like to express gratitude to J. Scott Shonkwiler, David K. Lambert and three anonymous reviewers for helpful comments on earlier drafts of this paper. This research was conducted under funding by the Nevada Agricultural Experiment Station Project No. 219, U.S. Department of Commerce, Economic Development Administration, University Center for Economic Development grant \#07-06-03262-95 and Western Rural Development Center.
} 
(Goldstucker et al., 1978). An approach to measure potential retail sales is trade area analysis. Trade area analysis estimates the number of people buying locally and yields information regarding retail sales capture or leakage from the community.

However, trade area analysis does not yield information about the impacts of exogenous variables affecting rural retail activity. An understanding of the influences of exogenous factors on trade area would provide additional behavioral information in the formulation and development of extension or outreach rural retail sector programs.

The primary objective of this paper is to develop analytical procedures to explain variations in rural retail trade activity. In pursuance of this objective, the paper is divided into five parts. First, the study area of this paper, the Great Basin region, is described. Second, trade area analysis procedures are discussed. Third, factors which influence rural retail sector activity are presented. Fourth, Tobit regression procedures are discussed as well as their potential application for analysis of rural retail sector activity. Finally, results of a tobit model are presented and implications for retail extension or outreach programs are discussed.

\section{STUDY AREA}

The study area is Nevada and Utah, which comprise the majority of the "Great Basin Region." 4 The geologic characteristics of the Great Basin are that its rivers have no outlet to the sea with elevations of the Great Basin ranging from 2,000 to over 13,000 feet. Precipitation varies from 3 to 5 inches in the deserts to approximately 60 inches in the high mountains. (Utah Division of Water Resources, 1976).

Population growth in the region has been fairly rapid during the 1980's. Population growth in the Great Basin area grew by 29.2 percent between 1980 and 1990 with the state of Nevada realizing a 50.5 percent growth rate during the period. Clark County, Nevada, which includes the city of Las Vegas, realized the highest growth rate of all Great Basin counties with an increase in population of 61 percent during the 1980 's.

Non-metropolitan counties in the Great Basin realized a population increase of 22.5 percent during the 1980 's. This growth rate lagged Great Basin metropolitan county population growth of 30.9 percent but far exceeded national non-metropolitan growth of approximately 4.0 percent during the 1980 's.

Even with population growth during the 1980's the non-metropolitan counties of the Great Basin continue to be sparsely populated. Population density 
for these non-metropolitan counties ranges from 293.4 persons per square mile in Carson City, Nevada to 0.4 persons per square mile in Esmeralda County, Nevada. Per capita incomes in 1990 for non-metropolitan counties in Nevada were $\$ 19,267$ and $\$ 12,554$ for Utah, while 1990 metropolitan county per capita income for Nevada was $\$ 20,429$ and $\$ 14,500$ for Utah. Differences in metropolitan and non-metropolitan income also influence rural retail sector activity.

Given the rapid population growth which has occurred in non-metropolitan counties within the Great Basin, the opportunities of expanded rural retail sector activity are evident. Given the current emphasis by Great Basin states to diversify their state economies to include tourism, an extension or outreach program detailing retail sector structure and identifying factors influencing rural retail sector activity is needed. The shift in state economies reflects the reduced dependency upon natural resource industries which act as the primary export-base industry. Economic revitalization thus requires improving a rural community's ability to capture local and recreational retail trade.

\section{TRADE AREA ANALYSIS}

Trade area analysis is rooted in central place theory. Central place theory predicts that a hierarchy of communities exists where the number of retail functions performed at a community increases as the size or order of a community increases (King 1984). Central place theory developed by Christaller (1966) and modified by Lösch (1954) conceptualized spatial linkages between population and retail trade functions performed as spatially related. The varieties of retail goods offered by a community depend upon demand and supply conditions locally as well as the distance a consumer would normally travel to obtain a particular good.

The adoption of central place theory to estimate rural commercial sector activity requires application of trade area analysis. A trade area as defined by Hustedde, Pulver, and Shaffer (1984) as a geographical area where a majority of customer demands for a specific commodity are met. Estimation of a trade area can be performed using either primary or secondary data. Primary data, usually derived from surveys, are expensive and time consuming, while secondary data sources are readily available at little or no cost. Two procedures which use secondary data sources are trade area capture and pull factor analysis. Trade area capture has been used widely to estimate sales potential for local economies (Chase and Pulver, 1983; Stone and McConnon, 1983; Hustedde et al., 1984; Shaffer, 1989; Harris, 1985; Harris et al., 1990). Trade area capture is based on 
the assumption that, after accounting for income differences, local tastes or preferences are similar to that of the state or reference area.

The trade area capture measure is a surrogate estimate of the number of customers or customer equivalents who purchase a specific type of merchandise (merchandise type i) in a given locality. With application to a county ${ }^{5}$, the standard approach used to derive trade area capture is presented by the following equation:

$$
\mathrm{TAC}_{\mathrm{ij}}=\frac{R S_{i j}}{\frac{R S_{i s}}{P O P_{s}} \cdot \frac{P C I_{j}}{P C I_{s}}}
$$

Where:

$\mathrm{TAC}_{\mathrm{ij}}$ is the trade area capture estimate for merchandise type $\mathrm{i}$ in county $\mathrm{j}$ $R S_{i j}$ is total sales of merchandise type $i$ in county $j$

$R S_{\text {is }}$ is total sales of merchandise type $i$ in state $s$

$\mathrm{POP}_{s}$ is population in state $\mathrm{s}$

$\mathrm{PCI}_{\mathrm{j}}$ is per capita income in county $\mathrm{j}$, and

$\mathrm{PCI}_{s}$ is per capita income in state $\mathrm{s}$

However, Stone (1986) and Yanagida et al. (1991) excluded the relative per capita income calculation, $\frac{P C I_{j}}{P C I_{s}}$ from their estimate of $\mathrm{TAC}_{\mathrm{ij}}$. Thus $\mathrm{TAC}_{\mathrm{ij}}$ is derived as:

$$
\mathrm{TAC}_{\mathrm{ij}}=\frac{\frac{R S_{i j}}{R S_{i s}}}{P O P_{s}}
$$

If trade area capture exceeds county population, the county is capturing outside trade. However, if the trade area capture is less than county population, the county is losing local retail trade. Comparison of the trade area capture estimates for specific retail sectors to total local retail trade provides insights as to which local retail sector is attracting customers from outside local boundaries.

The trade area capture estimate is an absolute rather than a relative measure of performance. It measures the total value of purchases made by residents and nonresidents. It is therefore difficult to use this measure for making comparisons with regions of different sizes and for assessing trends over time. For these purposes, the pull factor is used. The pull factor explicitly calculates the 
proportion of consumers that a county draws from outside its boundaries (i.e., tourists, residents from outside the county, etc.). The pull factor removes the influence of local population changes over time when determining changes in drawing power for a particular county. The pull factor is calculated by dividing the trade area capture estimate by the county population, or

$$
\mathrm{TAC}_{\mathrm{ij}}=\frac{T A C_{i j}}{P O P_{j}}
$$

Where:

$\mathrm{PF}_{\mathrm{ij}}$ is the pull factor for merchandise type $\mathrm{i}$ in county $\mathrm{j}$,

$\mathrm{TAC}_{\mathrm{ij}}$ is the Trade Area Capture estimate of merchandise type $\mathrm{i}$ in county $\mathrm{j}$, and

$\mathrm{POP}_{\mathrm{j}}$ is population in county $\mathrm{j}$.

A pull factor greater than one may be interpreted as the county attracting a larger number of customer equivalents than would normally be drawn from the local population assuming their level of purchases were similar to the statewide average. Conversely, a pull factor less than one implies that the retail purchases of local residents are not being captured by the local commercial sector.

If a community's or county's retail sector pull factor is less than one, programs may be designed to increase trade capture by the local retail sector. The results from trade area capture and pull factors do not yield information as to the determinants of trade and the efficiency of the local retail sector. Therefore pull factors alone may yield little information as to causes of retail sector leakages. With little or no knowledge of potential socio-economic factors and rural retail supply factors contributing to local retail sector leakages, formulating and presenting extension or outreach programs to strengthen local retail sector activity may fall short of anticipated goals.

\section{FACTORS INFLUENCING RURAL RETAIL TRADE ACTIVITY}

The lack of information about socio-economic factors and rural retail supply factors that may cause variation in local commercial sector activity is a deficiency in trade area analysis. However, pull factors calculated over time and compared to similar communities may help local decision makers evaluate the 
competitiveness of their local commercial sector. Unfortunately this may yield conclusions that may well be incorrect or unclear if statistical procedures are not followed.

Stone (1988) used cross-sectional data to investigate the impacts of shopping malls on rural Iowa retail sales. Stone (1988) found that if a mall is present in a county, total retail sales for the county increased by $\$ 75$ per additional square foot of mall space. However, when a mall is located outside the county and is within 25 miles of the county seat, total county retail sales decreased by $\$ 4.86$ for each additional square foot of mall space. When a mall is located outside the county and is within 26 to 50 miles of the county seat, county retail sales realized a loss of $\$ 0.61$ for each additional square foot of mall space.

Hamilton (1981) investigated the influence of population size and change on retail sales patterns in Queensland, Australia. Hamilton (1981) found that more populated communities achieved higher levels of per capita retail sales than less populated communities. However, close proximity to larger trade centers decreased per capita sales significantly. Hamilton's results also showed that declining or slow growing communities are more tenacious in holding onto local retail outlets, while faster growing communities are engaged in replacing small shops with large retail outlets.

Henderson (1990) estimated the elasticity of retail sales with respect to rural income. Henderson (1990) found that elasticities varied by type of retail business, source of income, and size of community. He concluded that alternative rural development strategies which change income sources in rural communities will yield different retail sales distributions.

Yanagida et al. (1991) developed an analytical framework for explaining both cross-sectional and intertemporal variations in pull factors for county retail sales in Nebraska. They found that lower retail sales leakages may be attributed to counties which are situated farther from trade centers, have larger federally adjusted gross incomes and experienced relatively lower population decreases. Specifically, for agricultural dependent Nebraska counties, the smaller the population of the largest town, the more significant the sales leakage.

Ayers et al. (1992) completed a study of rural retail businesses in thirty-seven communities in a three state study area of Indiana, Iowa and North Dakota. Their analysis identified demand and supply factors associated with above average retail sales. These factors included a more diverse local economic base, providing business management training and technical assistance, establishing a mechanism to increase transfer of business operations to new owners, developing financial assistance programs for new and aspiring businesses, and developing extension or outreach programs which help communities understand and cope with a changing economy. 
Harris and Shonkwiler (1994) employed household surveys and a bivariate two-limit Tobit model to derive factors for rural residents' shopping patterns. By incorporating dependency between different retail sectors, they found factors influencing rural retail shopping patterns could be more precisely defined. The results of their study suggest that rural retail sector outreach and extension programs should be broad based so that interdependencies among retail sectors can be captured.

In a pooled time series, cross-sectional analysis of Illinois rural areas, Gruidl and Andrianacos (1994) found demand factors played a central role in rural retail capture. County population and income levels were found to have significant impacts on rural retail trade expansion. However, structural elements underlying the supply side of the rural retail market, such as access and adoption of technological advances in retailing, were also found to be important components of rural retail trade.

Darling and Tubene (1996) investigated retail sector activity for 87 rural Kansas cities. Regression analysis indicated that city population alone explained significant variation in taxable retail sales. Kansas cities with populations over 5,000 consistently showed a net inflow of retail trade as measured by city pull factors.

Gale (1996) used time series data to investigate the relationship between retail sales and personal income in the computation of pull factors. Gale computed pull factors for 1982, 1987 and 1992 and found a trend toward increased sales leakages for more rural counties. Factors such as high population, density, lower farm reliance, larger county size and interstate highway access are associated with higher pull factors.

In many of these trade area analysis studies, the retail sectors were aggregated into a single retail sector where a pull factor was derived for aggregate retail trade. However, different segments of the local retail sector may differ in meeting demands of local consumers. Bhuyan (1996) found through disaggregated analysis of retail trade in North Dakota that niche markets for specific goods and services exist within rural counties in which these firms may effectively compete. Given the potential of differential retail sector coverage, economic development practitioners may want to target specific retail sector categories rather than the overall retail trade sector. Therefore, pull factors for the eight disaggregated retail sectors from 1992 Census of Trade were calculated and used for this analysis. ${ }^{6}$

Gruidl and Andrianacos (1994) concluded their paper by calling for better understanding of the forces influencing rural retail markets. If demand is found to be a major factor underlying rural retail trade, then public policy efforts should focus on expanding basic sector employment and income. However, if declines 
result from structural factors, then efforts to improve competitiveness of rural retailers must become a primary objective.

Also Yanagida et al. (1991) and Darling and Tubene (1996) employed ordinary least square procedures to investigate how changes in exogenous variables influence pull factor values. However, when rural retail extension or outreach programs are developed or when local economic development practitioners target retail sector development, the pull factor threshold value of one is of special importance in analyzing retail sectors. Retail sectors with pull factors greater than one means the local retail sector is not only meeting local consumer demands, but is also capturing consumer demand outside its borders. Therefore, statistical procedures which could yield information pertaining to exogenous factors which enhance capture not only of local consumers but of consumers outside a county's boundaries would be of interest to local economic development practitioners as well as rural retail extension and outreach personnel.

In order to estimate impacts of exogenous factors affecting pull factor values that are greater than or equal to one, censored regression procedures are employed. If a censored analysis is used, Amemiya (1973) among others have noted that the use of an ordinary least squares regression for censored data results in estimates that are inconsistent.

The statistical procedure used to correct for censored data estimation problem is the Tobit model. ${ }^{7}$ According to Peddle (1987), the Tobit procedure recognizes the special nature of threshold values of independent variables and makes use of the information contained in counties and retail sector categories which are less than one. The Tobit procedure recognizes all pull factors less than one as zero and those equal to or greater than one as their calculated value. The Tobit model analyzes first the difference between zero and non-zero values then differentiating on the basis of explanatory variables, between varying pull factor values greater than one.

\section{MODEL SPECIFICATIONS}

The stochastic model underlying the Tobit model can be represented by:

$$
\begin{aligned}
& Y_{i}=\beta^{\prime} X_{i}+\varepsilon \quad \text { if } Y_{i}>O \\
& Y_{i}=O \quad \text { Otherwise }
\end{aligned}
$$

Where $\beta$ is a (kx1) vector of unknown parameters; $X_{i}$ is a $(\mathrm{kx} 1)$ vector of independent variables. The random variable $\varepsilon$ is assumed to be normally 
distributed with zero mean and constant variance, $\sigma^{2}$. If (4) is defined in a latent variable framework, with:

$$
\mathrm{Y}^{*}=\mathrm{X} \boldsymbol{\beta}^{\prime}+\varepsilon
$$

and the latent variable is defined $Y_{i}^{*}$ as the desired or potential level of pull factors, and $\mathrm{Y}_{\mathrm{i}}$, the observed variable, as:

$$
\begin{array}{ll}
Y_{i}=Y_{i}^{*} & \text { if } Y_{i}^{*} \geq 1 \\
Y_{i}=O & \text { Otherwise }
\end{array}
$$

and the expected values for $Y_{i}$ given that only values above one are used is given by:

$$
E\left(Y_{i}^{*}\right)=\beta^{\prime} X_{i}
$$

The objective is to predict retail potentials for those observations having pull factors greater than one or censored at one. Therefore, observations that are greater than zero but less than one are censored at zero. Expression (7) corresponds to the earlier statements pertaining to pull factors which are greater than one.

Consistent estimation of model (5) is obtained through maximum likelihood techniques (Amemiya 1973; Tobin 1958). The likelihood function for the $n^{\text {th }}$ observation $(n=1,2, \ldots, N)$ of the one limit Tobit model censored at one for the estimation of the parameters $\beta$ and $\sigma^{2}$ is

$$
L\left(\beta, \sigma^{2} Y\right)=\prod_{y_{i}>1} \frac{1}{\sigma} \varnothing\left(\frac{Y_{i}-\beta^{\prime} X_{i}}{\sigma}\right) \prod_{y_{i} s} \Phi\left(\frac{1-\beta^{\prime} X_{i}}{\sigma}\right)
$$

where $\varnothing($.$) and \Phi($.$) are, respectively, the density function and the distribution$ function of the standard normal density.

The corresponding likelihood function for the Tobit regression model censored at zero is

$$
L\left(\beta, \sigma^{2} Y\right)=\prod_{y_{i}>0} \frac{1}{\sigma} \varnothing\left(\frac{Y_{i}-\beta^{\prime} X_{i}}{\sigma}\right)_{y_{i} \leq 0} \Phi\left(\frac{1-\beta^{\prime} X_{i}}{\sigma}\right)
$$

As Tobin (1958) shows, the locus of expected values for $Y_{i}$ given that all observations are used is given by: 


$$
E\left(Y_{i}\right)=\Phi_{i} \beta^{\prime} X_{i}+\sigma \varnothing_{i}
$$

and $\varnothing($.$) and \Phi($.$) are as defined.$

Equations (7) and (10) are both of interest because they can be used to evaluate how a change in a conditioning variable affects the conditional expected values of $Y_{i}$. These results should play a role in the development of rural retail extension or outreach programs.

From the 1992 Census of Retail Trade (1994), county and state sales for eight retail sectors were derived for estimation of county trade area capture and pull factors. The pull factor for each of these eight retail sectors in a given county is a relative measure of trade activity for these retail sectors. The extent of retail sales for each of the eight sectors is a function of both market demand and supply for the eight sectors. Tobit regression procedures were employed to derive the influence of exogenous factors on retail pull factor values of one or higher. This threshold value signifies that the local retail sector is meeting demands not only of local consumers but also of those outside the county boundaries. This study differs from most market threshold or trade activity studies because the unit of observation is the county as opposed to town or city. Therefore, it is anticipated that the trade area activity calculations will not be directly comparable to estimates at the town or city level.

Given the small sample size $(n=39)$, a Tobit type formulation is adopted not because the data are considered to be censored, but because there are not sufficient observations to fit different statistical models to the different processes (Maddala 1985). A Tobit type formulation is somewhat restrictive since it considers that the factors which explain the probability of positive pull factors also affect the levels of the pull factors. Its use is statistically justified given the large number of discrete (zero) outcomes. The Tobit equation combining both supply and demand for the eight retail sectors is given as:

$$
\begin{aligned}
\mathrm{PF}= & \mathrm{f}(\mathrm{PCI}, \mathrm{AGE}(18-64), \text { AGE (65+), LARGTOWN, DMA, } \\
& \text { RETOUT, SCALE, DUMMY) }
\end{aligned}
$$

Where:

PF is the pull factor value for a given retail sector of nonmetropolitan Great Basin county;

$\mathrm{PCI}$ is county per capita income;

AGE (18-64) is percent of each county's population between the ages of 18 and 64 relative to the state; 
AGE (65+) is percent of each county's population 65 years and older relative to the state's value;

LARGTOWN is population of largest town in the county;

DMA is distance to the nearest SMSA from the county seat of the non-metropolitan county;

RETOUT is the number of retail outlets in a given non-metropolitan county

SCALE is a retail sales scale index that is the ratio of county sales per establishment to state sales per establishment;

DUMMY is a dummy variable where one is for counties adjacent to metropolitan counties and zero otherwise.

From previous studies, demand factors such as per capita income, percentage of county population between the ages of 18 and 64 relative to the state; percent of each county's population 65 years and older relative to the state, population of largest town in the county, distance to nearest metropolitan county, number of retail firms in a county, and whether the non-metropolitan county is adjacent to a metropolitan county are suggested. As opposed to previous studies where rural retail trade was aggregated, the differential effects of the demand factors on different retail sectors in this analysis can be derived.

For demand factors, such as per capita income, it is hypothesized that as county per capita incomes increase, demand for retail goods will increase. Percent of county's population between 18 and 64 relative to the state should incorporate the mobility of the younger or working age population as well as the demands of families with more than two members. Given that the retired population [Age (65+)] is less mobile and mainly consists of only one or two members of the household, its impact on local retail demand may differ from that of the working age population. For demand factor LARGTOWN, counties with towns of larger population would have the potential to become trade centers and increase trade area capture. Distance to metropolitan county incorporates the disutility of transportation. The further away from a metropolitan area, the greater the propensity for higher relative trade area activity. The dummy variable for non-metropolitan counties adjacent to metropolitan counties captures those interrelated effects between non-metropolitan counties and the metropolitan counties where major retail sectors exist. The potential impacts of agglomeration and economies of scope for shoppers is captured by the number of retail outlets in a non-metropolitan county. The higher the number of retail firms, the greater the influence of agglomeration and therefore local trade area activity.

To incorporate the supply factors of rural retail trade, a variable which incorporates the effect of firm size was developed. This variable calculates sales scale effects by dividing the sales per establishment for a county to sales per 
establishment for the state. The higher the sales scale index, the higher the trade area capture. This variable incorporates the influence of local retail sales size per establishment and its importance to local retail trade activity.

Per capita income, population of largest town in a county, distance to nearest SMSA and number of retailers in the county were transformed into log values. The dummy variable was employed to capture the impact of nearness to a metropolitan county. Structural factors also influence sales retention within a rural county. The influence of scale of rural retail sector on sales retention is derived through the scale index of county sales per establishment to state sales per establishment. Maximum likelihood estimations through the LIMDEP software program (Greene 1992) were employed in order to derive consistent and efficient parameter estimates.

Tobit coefficients can provide economic and policy insights through procedures outlined by McDonald and Moffit (1980). The McDonald-Moffit technique calculates a fraction by which the Tobit coefficients may be decomposed into two effects. Part one of the decomposition represents the effect of a change in an exogenous factor on the probability of the dependent variable being above the limit (i.e., a retail sector's pull factor is above one). The second part is the effect of a change in exogenous variables on the dependent variable assuming the dependent variable is already above the limit (i.e., a retail sector's pull factor is greater than one). McDonald-Moffit argue that coefficients must be adjusted by the second fraction to obtain regression effects for observations above the limit. Results of both parts of the McDonald-Moffit procedures would yield information to extension or outreach personnel in developing retail sector education programs. As for local economic development professionals, results of the McDonald-Moffit analysis would provide information to either strengthen a local retail sector economy or to maintain viability of an already successful local retail sector.

\section{RESULTS}

Table 1 shows sample characteristics for variables employed in this analysis. Pull factor averages ranged from 0.3709 for furniture and home furnishings to 1.0591 for food stores. General merchandising had the highest pull factor of 6.202 followed by apparel and accessory stores with 5.274 . Only 10.25 percent of the counties had pull factors greater than one for retail sectors, apparel and accessory stores; furniture and home furnishing stores; and miscellaneous retail stores. The food stores sector had pull factors greater than one in 41 percent of the counties. 


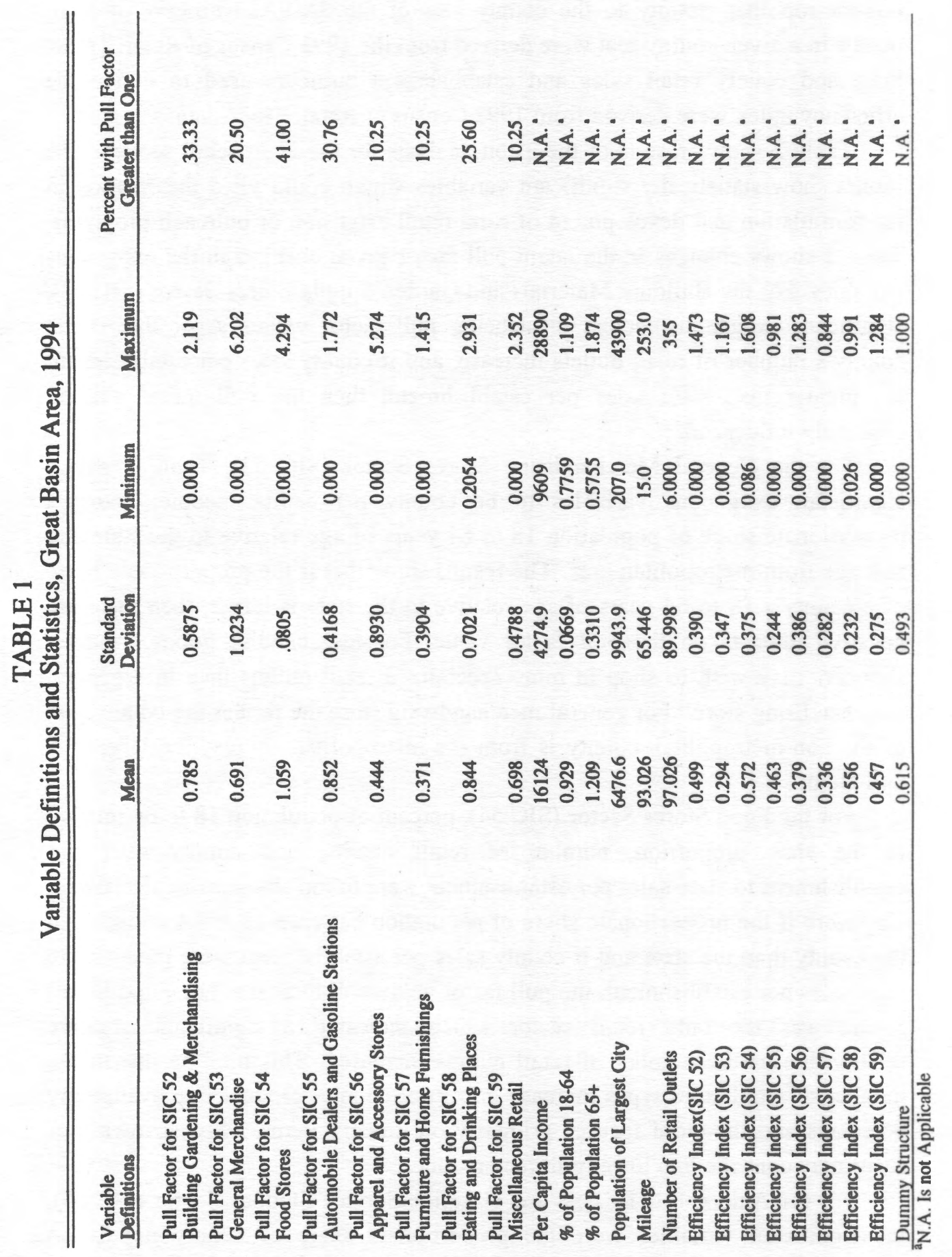


Demographic data for variables LARGTOWN, AGE (18-64), and AGE $(65+)$ were obtained from the U.S. Bureau of Census. Distance to nearest Metropolitan Statistical Area (SMSA) was estimated from the county seat of the non-metropolitan county to the county seat of the SMSA. Numbers of retail outlets in a given county seat were derived from the 1992 Census of Retail Trade. State and county retail sales and establishment numbers used to derive the efficiency index were derived from 1992 Census of Retail Trade data.

Table 2 shows results of the Tobit analysis for the eight retail sectors. The results show statistically significant variables which could yield information in the formulation and development of rural retail extension or outreach programs. Table 2 shows changes in the latent pull factor given changes in the exogenous variables. For the Building Materials and Garden Supply Stores Sector (SIC 52), significant exogenous factors influencing pull factor values show that if the county's number of retail outlets increase, and if county sales per establishment are greater than state sales per establishment, then the pull factor will be positively influenced.

For the General Merchandising Stores Sector (SIC 53), Table 2 shows significant exogenous variables to be county per capita income, county's proportionate share of population 18 to 64 years of age relative to the state and mileage from metropolitan area. The results show that if the proportionate share of a county's 18 to 64 years of age relative to the state is larger, then there are negative impacts on the pull factor value. For merchandise goods, younger shoppers may wish to shop in more specialized retail outlets than in a general merchandising store. For general merchandising store the farther the county seat of the non-metropolitan county is from the metropolitan county, the larger the pull factor.

For the Food Stores Sector (SIC 54), percent of population 18 to 64 relative to the state proportion, number of retail outlets, and county sales per establishment to state sales per establishment were found statistically significant. Therefore if the proportionate share of population between 18 to 64 is higher in the county than the state and if county sales per establishment were greater than state sales per establishment, the pull factor value will increase. The Food Stores Sector was the only retail sector which indicated a significant negative relationship as the number of retail outlets increased. This may be due to the number of retail store types increase in a rural county, product line availability decreases and the store focuses primarily on grocery items. This narrowing of focus may contribute to lower pull factor values.

For the Automobile Dealers and Gasoline Service Stations Sector (SIC 55), the significant variables were the proportionate share of county population greater than 65 years of age relative to the state, the scale index, and the dummy 


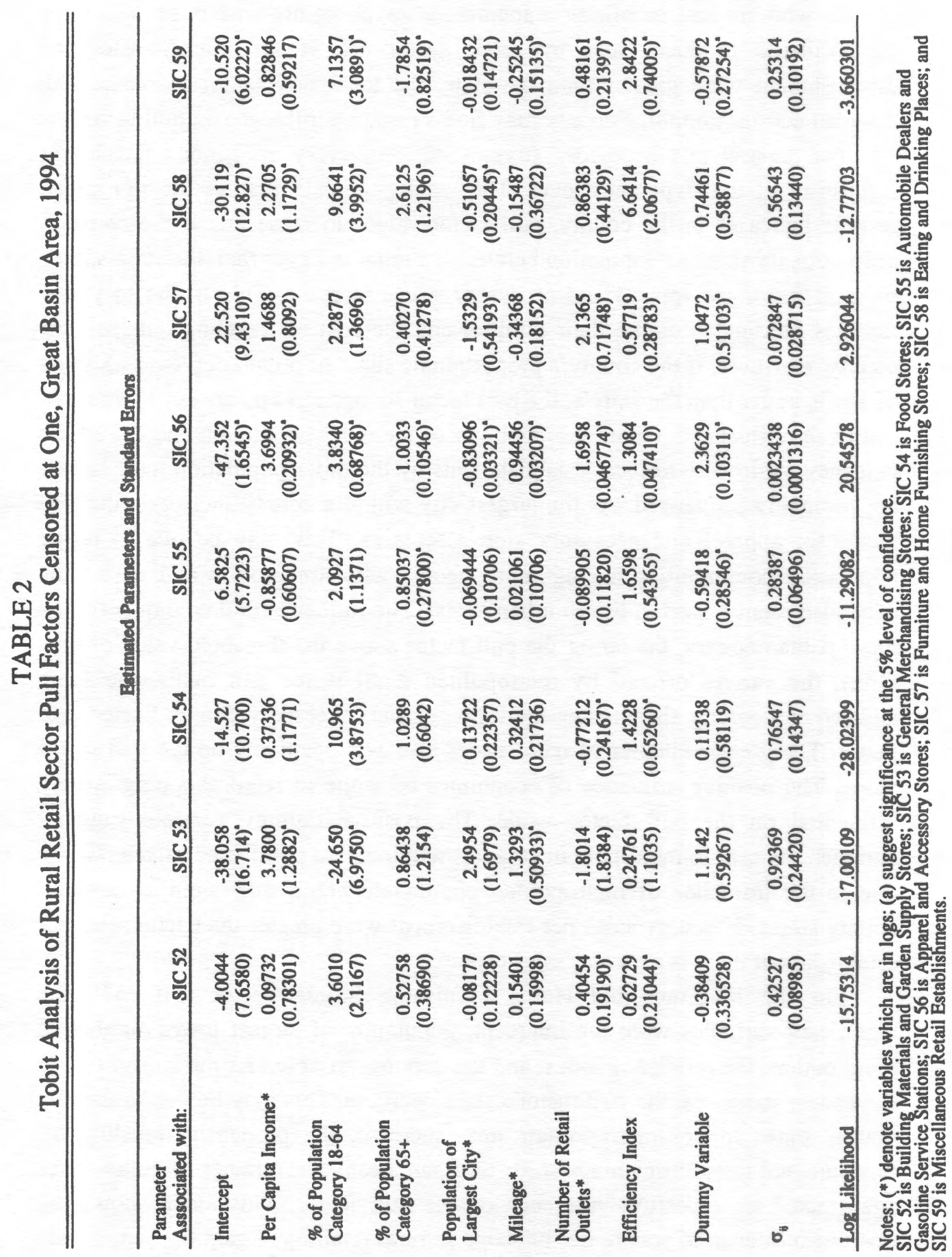


variable. Therefore, if a county's proportionate share of population 65 years and older is greater than the state's proportionate share, the pull factor for Automobile Dealers and Gasoline Service Stations Sector increases. Older people, who are less mobile will apparently travel mainly within the local area for available products sold by retail sector 55 . If the county sales per establishment were greater than the state, the local pull factor increased. An adjacent non-metropolitan county may find a negative influence on pull factor.

For apparel and accessory stores (SIC 56), every exogenous factor was significant at the 5 percent level. The results indicate that as the per capita income increases in the county, pull factor values increase and if the county's proportionate share of population between 18 to 64 is larger than the state's, then the pull factor for apparel and accessory stores increase. This is due to young families needing to clothe their families and the cost of traveling outside their county. However, if the county's proportionate share of population over 65 years of age is larger than the state's, the pull factor for apparel and accessory stores is positively influenced. Given less mobility of the older population and the higher tendency for loyalty to local establishments by the older population, pull factors are positively influenced. As the largest city within a county increases, the pull factor for apparel and accessory store decreases. This may be due to larger population communities having more people who are mobile and desire the expanded retail opportunities in urban areas. The further a rural county is from a metropolitan county, the larger the pull factor above the threshold value of one. Given the variety offered by metropolitan retail stores and malls, the more isolated the county the greater the Apparel and Accessory Stores Sector pull factor. The greater number of retail stores also acts positively on the pull factor value. The positive influence of economies of scope in retail shopping is very influential on the pull factor value. The positive dummy variable suggests counties adjacent to metropolitan counties will increase pull factor values. This is due to the influence of metropolitan population which may shop at adjacent county stores. If county sales per establishment were greater than state sales per establishment there is a greater sales capture.

For the Furniture and Home Furnishing Stores Sector (SIC 57), the significant variables were the intercept, population of largest town, number of retail outlets, the efficiency index, and the dummy variable. As the largest city in the county increases, the pull factor values decrease. This may be due to the fact that as cities in non-metropolitan areas increase, the propensity to shop for furniture and home furnishings shifts to urban areas. The number of outlets once again acted as a positive influence on the pull factor. This again shows the positive influence of economies of scope in rural retailing. Again the supply side factor is significant. That is, if the retail sector sales per establishment increases, 
the pull factor will increase. Also the dummy variable implies that non-metropolitan counties adjacent to metropolitan counties actually increase the pull factor due to metropolitan customers purchasing furniture and home furnishings in non-metropolitan areas.

For the Eating and Drinking Places Sector (SIC 58), the intercept, per capita income, proportion of county population between 18 to 65 years to the state proportion of county population 65 years or greater to the state, population of largest city, number of retail outlets, and efficiency index were all significant factors. If a county's per capita income increases, the trade capture for eating and drinking is higher. This relates to higher incomes eating outside the home more often than lower income consumers. If a county's proportionate share of population between 18 to 64 is larger than the state's proportionate share, the eating and drinking places pull factor will increase. This is due to the working age public's higher propensity to dine outside the home. Similarly, if a county's proportionate share of population 65 years and older is larger than the state's share, the value of the pull factor increases. This is due to lower mobility in the retirement age category and their propensity to dine outside the home. In addition, if the population of the larger community within a county increases, the pull factor decreases. This may be due to larger non-metropolitan county population's propensity to dine outside of the county. As the number of retail outlets increases, the pull factor for eating and drinking places increases. This shows dependency between retail sectors. In addition, if the county sales per establishment were greater than the state, there will be a higher pull factor. The dummy variable for being adjacent to metropolitan counties is positive. This means that adjacent non-metropolitan counties capture metropolitan county eating and drinking sector consumption.

For the Miscellaneous Retail Sector (SIC 59), at the five percent level proportionate share of population 18 to 64 years, proportionate share of population 65 years and older, number of retail outlets, scale index, and dummy variables are significant. Therefore for miscellaneous retail, if the county's proportionate share of population 18 to 64 is greater than the state's share, the pull factor will be greater. This finding would seem to indicate that the working age population has a higher propensity to purchase items covered by the Miscellaneous Retail Sector. In addition, the older the population, the less pull factor for miscellaneous retail goods. The number of retail outlets and retail sales scale index, are positive influences. Being adjacent to a metropolitan county reduces pull factor.

An interesting aspect of this analysis was to examine the implication of predicting retail potentials when pull factors are censored at zero or one. If a local economic development practitioner or extension/outreach personnel is only 
interested if a retail sector category exists within a given county, pull factors censored at zero would be adequate. However, if the local economic development or extension/outreach person is interested in estimating the local trade sector's ability to capture trade outside of its boundaries, then pull factors censored at one would be of importance. Given the shift in local government revenue sources from property taxes to sales taxes, capturing local and outside taxable sales has become an area of interest for many local government officials.

Table 3 shows the conditional expectations for each retail sector taken independently of other sectors and results are averaged over the entire sample. For example, the expected values for the Building Materials and Garden Supply Sector and the General Merchandising Sector for threshold value censored at one are 1.1547 and 1.2313 , respectively. While expected values for the same sectors censored at zero are 0.7798 and 0.7670 , respectively. Therefore the expected pull factor values for the Building Materials and Garden Supply Stores Sector and the General Merchandising Sector are approximately 47 percent and 61 percent greater, respectively, if it is known that the county's selected retail category is capturing sales outside of its boundaries.

TABLE 3

Conditional Expectations of Rural Retail Sector Pull Factors, Great Basin Area, 1994

\section{Variables}

$E(Y)=E[Y / y>0] \quad E(Y)=E[Y / y>1]$

SIC 52

Building, Gardening \& Merchandise $\quad 0.7798$

SIC 53

General Merchandise

0.7670

SIC 54

Food Stores

SIC 55

Automobile Dealers and Gas Stations

SIC 56

Apparel and Accessory Stores

SIC 57

Furniture and Home Furnishings

SIC 58

Eating and Drinking Places 
Comparing these expected pull factor values, it becomes evident why rural economic development practitioners and extension/outreach personnel become very interested in capturing local and external retail trade. Not only are the expected pull factors for sectors with a pull factor greater than one larger but these rural counties and communities on average capture higher taxable sales for local government revenues. Therefore extension and outreach programs which provide information to rural decision makers as to maintaining and expanding retail trade capture would be of interest.

\section{Decomposition of Tobit Results}

McDonald and Moffit (1980) have shown that the Tobit coefficients can provide additional information with both economic and policy implications. The McDonald-Moffit technique estimates the two effects of decomposition of Tobit results. First, decomposition represents the effect of a change in an exogenous variable on the probability that the dependent variable being above the limit (i.e. a retail sector with a pull factor equal to one). The second decomposition shows the effect of a change in the exogenous variable on the dependent variable assuming the dependent variable is already above the limit (i.e., sectoral pull factor is greater than one). Coefficients of the first decomposition provide information to extension/outreach personnel as to how changes in exogenous variables would increase the probability of a local retail sector meeting the demands of the local populace. Coefficients of the second decomposition provide information to extension/outreach personnel about how a county which has a pull factor greater than one can maintain and expand its retail capture.

Coefficients shown in Table 4 represent the relationship between a change in county characteristics and a change in the expected pull factor for a county capturing trade outside of its boundaries. The amount of adjustment depends upon the proportions of the sample that is not at the limits, with a higher proportion resulting in a smaller reduction of the coefficient. In this study, the proportion of the pull factor that is not at the limit ranges from 10.25 percent for the Apparel and Accessory Store, the Furniture and Home Furnishing Sector, and the Miscellaneous Retail Sector to 41 percent of counties for the Food Stores Sector.

The resulting coefficients from applying the McDonald-Moffit procedures are shown in Table 4. Evaluated at their sample means, $\frac{\partial E\left(y_{1} \mid y_{i}>1\right)}{\partial X_{j}}$, the coefficients for each retail sector are the relationship 


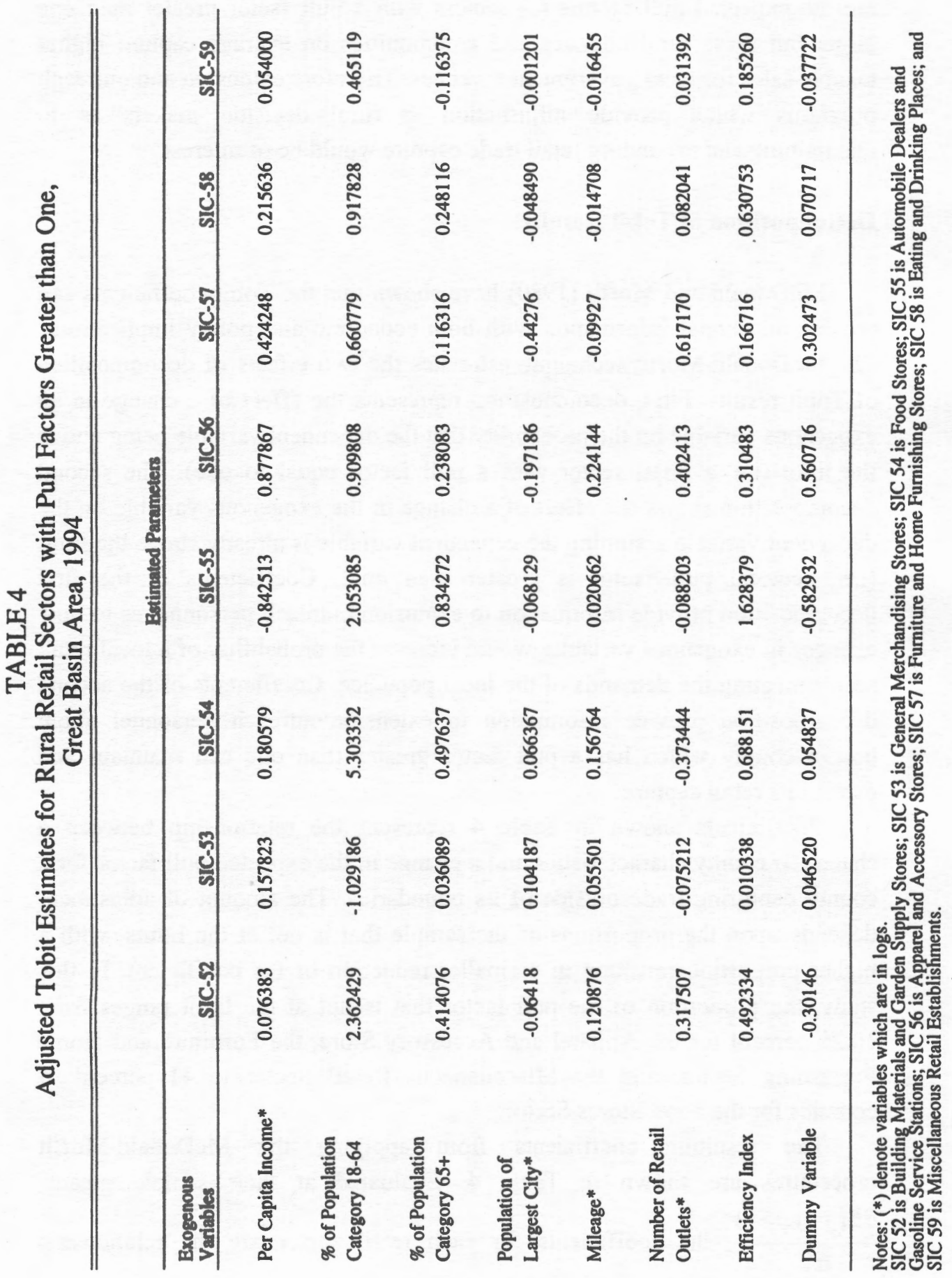


between a change in the independent variable and the expected pull factor for a given sector which has a pull factor greater than one. In comparing coefficients in Tables 2 and 4, the adjusted coefficients are less closely related to changes in county characteristics than indicated by the Tobit results. Specifically, adjusted coefficients of SIC 53 or the General Merchandising Sector are about $4 \%$ the magnitude of the aggregate Tobit estimates and for SIC 56 or the Apparel and Accessory Stores Sector the adjusted coefficients are about $25 \%$ of the original estimates. These comparisons indicate that the selected county characteristics were better at differentiating between counties with a retail sector pull factor greater than or equal to one than predicting pull factor value differences for counties losing retail trade capture. An alternative analysis would be that changes in selected county characteristics have a much larger impact on the probability of county's retail sector having a pull factor greater than or equal to one given the county is currently not capturing local trade than on the possibility of increased trade capture for a county's retail sector whose pull factor is already greater than one.

\section{CONCLUSIONS}

Rural economic development has long focused the location or relocation of manufacturing plants to a rural area. Often these development goals are risky and areas which provided inducements for industrial location may find results less than what was anticipated. An alternative to industrial relocation is development of the local commercial sector.

The focus on rural retail sector development has increased with USDA Extension focusing on formulation and development of rural retail extension education and outreach programs. However, before programs are formulated necessary research investigation is required. This paper investigated the influence of exogenous factors on pull factor estimates below and above the threshold value. The threshold for pull factors is one meaning that the local retail sector is capturing retail trade not only in the local community but outside its boundaries. Using Tobit procedures, significant exogenous factors were found. An interesting finding is the impact of number of retail trade stores. With a larger number of retail stores, economies of scope are realized by the rural customer which yields higher pull factors. Also, the influences of exogenous factors on different retail sector categories may have different impacts which should be included in an extension or outreach retail sector program. In addition, results agree with findings of Gruidl and Andrianacos (1994) in that supply factors as well as demand factors must be addressed to increase rural retail sector activity. 


\section{ENDNOTES}

1. The five general strategies suggested by Pulver (1979) are: (1) attract new basic employers; (2) improve efficiency of existing firms; (3) improve ability to capture dollars; (4) encourage new business formation; and (5) increase aids/transfers received from broader governmental levels or units.

2. Numerous research and extension programs have been undertaken in the nation. Most notable has been a retail extension program by Ken Stone at Iowa State University Cooperative Extension while outreach programs have been delivered by the Small Business Development Centers across the nation.

3. The National Small Store (Retailer) Consortium has been created by the USDA Extension to address and formulate rural retail extension programs.

4. The Great Basin also depicts a water basin of the Water Resources Council.

5. Equation 1 outlined can also be related to the community level. If retail data is available, community level analysis would be preferred. However in some states, sales taxes are not collected and where sales taxes are collected, retail sales may be recorded at regional or state headquarters rather than at point of sale. Therefore, Census of Retail Trade sales values were used because of the reliability of the values for both Nevada and Utah.

6. The eight retail sectors used in this analysis were: Building Materials and Garden Supply Stores (SIC 52); General Merchandising Stores (SIC 53); Food Stores (SIC 54); Automotive Dealers and Gasoline Service Stations (SIC 55); Apparel and Accessory Stores (SIC 56); Furniture and Home Furnishing Store (SIC 57); Eating and Drinking Establishments (SIC 58); and Miscellaneous Retail Establishments (SIC 59).

7. A detailed explanation of Tobit procedures is given in a referenced study by Greene (1993).

\section{REFERENCES}

Amemiya, Takeshi. "Regression Analysis when the Dependent Variable is a Truncated Normal." Econometrica 41 (1973):997-1016.

Ayers, Janet S., F. Larry Leistritz and Kenneth E. Stone. "Revitalizing the Retail Trade Sector in Rural Communities: Lessons from Three Midwestern States." Ames, Iowa: North Central Regulatory Center for Rural Development RRD12, November 1992. 
Chase, Robert A. and Glen C. Pulver. "The Impact of Shopping Centers on Downtowns of Small Non-metropolitan Communities." Journal of the Community Development Society 14(1983): 51-66.

Christaller, Walter. "Die Zentrulen Orte in Suddeutschland," Jena, Germany:

Fisher, 1933. English translation by C. Baskin. "The Central Places of Southern Germany." Englewood Cliffs, N.J.: Prentice-Hall, 1966.

Daniels, Thomas L. "Small Town Economic Development: Growth or Survival?" Journal of Planning Literature 4(1989):413-429.

Darling, David L. and Stephan L. Tubene. "Determining the Population Thresholds of Minor Trade Centers: A Benchmark Study of Non-Metropolitan Cities in Kansas." Review of Agricultural Economics 18(1996):95-102.

Gale, Jr., H. Frederick. "Retail Sales Pull Factors in U.S. Counties." The Review of Regional Studies 26(1996):177-196.

Goldstucker, Jac L., Danny N. Bellenger, T. Stanley and R. Otte. New Developments in Retail Trading Area Analysis and Site Selection. Atlanta, GA: College of Business Administration, Georgia State University, 1978.

Greene, William H. Econometric Analysis. 2nd edition, New York: MacMillan, 1993.

Greene, William H. LIMDEP User's Manual and Reference Guide, Version 6.0. Bellport, New York: Econometric Software, Inc., 1992.

Gruidl, John J. and Dimitri Andrianacos. "Determinants of Rural Retail Trade: A Case Study of Illinois." The Review of Regional Studies 24(1994):103-118.

Hamilton, Joel R. Population Change and Retail Sales Patterns in Local Authority Areas of Queensland. University of Idaho, Department of Agricultural Economics, Ag. Econ. Research Report \#369, Moscow, Idaho, 1981.

Harris, Thomas R. "Commercial Sector Development in Rural Communities: Trade Area Analysis." Western Rural Development Center, Oregon State University, Corvallis, Oregon, WREP-90, 1985.

Harris, Thomas R and J. Scott Shonkwiler. "Application of Maximum Likelihood to a Bivariate Two-Limit Tobit Model for Estimation of Rural Retail Sales Potential." The Review of Regional Studies 24(1994):143-160.

Harris, Thomas R., Gary W. Smith and Michael B. Mooney. "An Alternative Approach to Trade Area Analysis." Journal of the Community Development Society 21(1990): 116-128.

Henderson, David. "Rural Retail Sales and Consumer Expenditure Functions." The Journal of Agricultural Economics and Resources 42(1990):27-34. 
Hustedde, R., Glen C. Pulver, and Ron. Shaffer. Community Economic Analysis: A How to Book. Ames, Iowa: North Central Regional Center for Rural Development, 1984.

King, Leslie J. Central Place Theory. London: SAGE Publications, 1984.

Lösch, August. The Economics of Location. tr. W. H. Woglom, New Haven, CT: Yale University Press, 1954

Maddala, G.S. "A Survey of the Literature on Selectivity Bias as It Pertains to Health Care Markets" in Advance in Health Economies and Health Services Research, Vol. 6, JAI Press, 1985.

McDonald, James B. and Robert A. Moffit. "The Use of Tobit Analysis." Review of Economics and Statistics 62(1980):318-321.

Peddle, Michael T. "The Appropriate Estimation of Intrametropolitan Firm Location Models: An Empirical Note." Land Economics 63(1987):303-305.

Pulver, Glen C. "A Theoretical Framework for the Analysis of Community Economic Development Policy Options." In Nonmetropolitan Industrial Growth and Community Change. ed. G. Summers and A. Selvik, 105-108, Lexington, MD: D.C. Health-Lexington Books

Shaffer, Ron. Community Economics: Economic Structure and Change in Smaller Communities. Ames, Iowa: Iowa State University Press, 1989.

Stone, Kenneth E. and James C. McConnon, Jr. "Historical Analysis of Retail Sales of Britt and Surrounding Areas." Iowa State University, Iowa State Extension Fact Sheet, Ames, Iowa, 1983.

Stone, Kenneth E. "Impact of the Farm Financial Crisis on the Retail and Service Sectors of Rural Communities." Agricultural Finance Review Special Issue (1986): 41-47.

Stone, Kenneth E. "Trade Area Analysis-A Catalyst for Community Development." Proceedings of the Community Economic Development Strategies Conference. Ames, Iowa: North Central Regional Center for Rural Development, 1988.

U.S. Department of Commerce. 1992 Census of Retail Trade: Utah. Washington, D.C. Bureau of Census, 1994.

U.S. Department of Commerce. 1992 Census of Retail Trade: Nevada. Washington, D.C. Bureau of Census, 1994.

U.S. Department of Commerce. "Regional Economic Information System." Washington, D.C.: Bureau of Economic Analysis, 1995.

Utah Division of Water Resources. Main Report: Great Basin Region Comprehensive Framework Study. Salt Lake City: U.S. Water Resources Council, 1976. 
Yanagida, John F., Bruce B. Johnson, Joel Young and Michael Lundeen. "An Analysis of Economic and Non-economic Factors Affecting Retail Sales Leakages." The Review of Regional Studies 21(1991):53-64. 